\title{
THE NEED FOR CROSS-CULTURAL ADAPTATION OF INTERNSHIP FOR THE CHINESE SUBSIDIARY OF DANONE \\ Irina Sidorcuka ${ }^{1}$, Madina Nigmatullaeva ${ }^{2}$
}

\begin{abstract}
Multinational corporations with subsidiaries worldwide are challenged by the need to communicate with and manage people different in their beliefs, behaviors, cultural values. This paper is focused on the case of Chinese interns in Danone, France. Danone is facing a severe shortage of skilled workforce in China for that reason that the company is willing to "groom" professionals externally for their Chinese subsidiary by engaging Chinese studens in internship programs within its headquarters in France. Despite the high number of Chinese students joining the internship programme each year, only few of them demonstrate a willingness to join the company upon accomplishment of the internship. Therefore the task of this study was to investigate the reasons behind such poor motivation of Chinese interns to stay in Danone through an analysis of French and Chinese cultural dimensions, proposed by key researchers in the field, as well as the empirical research of Chinese interns dissatisfaction causes through qualitative and quantitative research. The study reveals the key cultural values and attitudes of Chinese interns that have caused their dissatisfaction within french management and demonstrates that there is a mismatch between the expectations and preferencies of Chineses interns in communication and networking, time management, job distribution and staff reward and other job-related issues and the way these are dealt with in Danone.
\end{abstract}

JEL Classification Numbers: A23, A29, M53; DOI: http://dx.doi.org/10.12955/cbup.v6.1194

Keywords: internship, dissatisfaction, cross-cultural challengies, Danone,multinational, Chinese subsidiary

\section{Introduction}

Intensive globalization, leading to the expansion of corporations into new markets, brought numerous challenges including the demand of powerful multinational organizations for effective leaders, who would manage the culturally diverse workforce. This, in fact, generated the need to understand the influence of cultural diversity on management and leadership practices (House et al., 2004). A lot of studies have been carried out to test the relationship between culture and different attributes of management including employees' motivation, reward systems, hierarchy, and different forms of leadership (Harzing and Pinington, 2014).

Danone, as a powerful French multinational expanding into the Chinese market, is an example of such a corporation engaging in the above-mentioned processes, which is the focus of this research paper.

Economic and social conditions of the Chinese labor market, along with aggressive recruitment campaigns of competitors made Danone face a shortage of skilled workforce in its subsidiary in China. According to the statistics provided by the center of International Education Benchmarking (2015), only $4 \%$ of the labor force in China constitute highly-skilled and $20 \%$ - skilled workers respectively. Therefore, Danone, facing the challenge of finding, training and employing new staff, who can contribute to its success in China, decided to prepare the talents externally to solve the problem of employees' scarcity. Each year, the company engages Chinese students in internship programmes to introduce them to the company's vision and strategies, provide conditions for knowledge gaining, to make them efficient and operational and prepare them for further recruitment by the company. (Danone, 2006) As presented in the Figure 1, within the last four consequent years a total of 148 Chinese students have been trained in the internship programmes within Danone, France. At least $64 \%$ of the Chinese students where expected to stay with the company but, only $36 \%$ of them decided to stay (Danone, 2017).

The most frequently reported issues to cause low motivation and the lack of willingness to stay within the company among the 107 questioned Chinese interns were the following: ways of organising work, problems of communication and relationships with supervisors, system and practises of rewards distribution, engagement in debates, lack of time dedicated to internal networking among staff. The question arises whether these areas of dissatisfaction are based on culturally embedded differences in French and Chinese management, leadership, communication and other work-related issues.

\footnotetext{
${ }^{1}$ RISEBA University, 3 Meza str., Riga, Latvia, irina.sidorcuka@ riseba.lv

${ }^{2}$ European Society for Vascular Surgery, 39 rue du Chateau d'Eau, Bordeaux, France, m.nigmatullaeva@gmail.com
} 


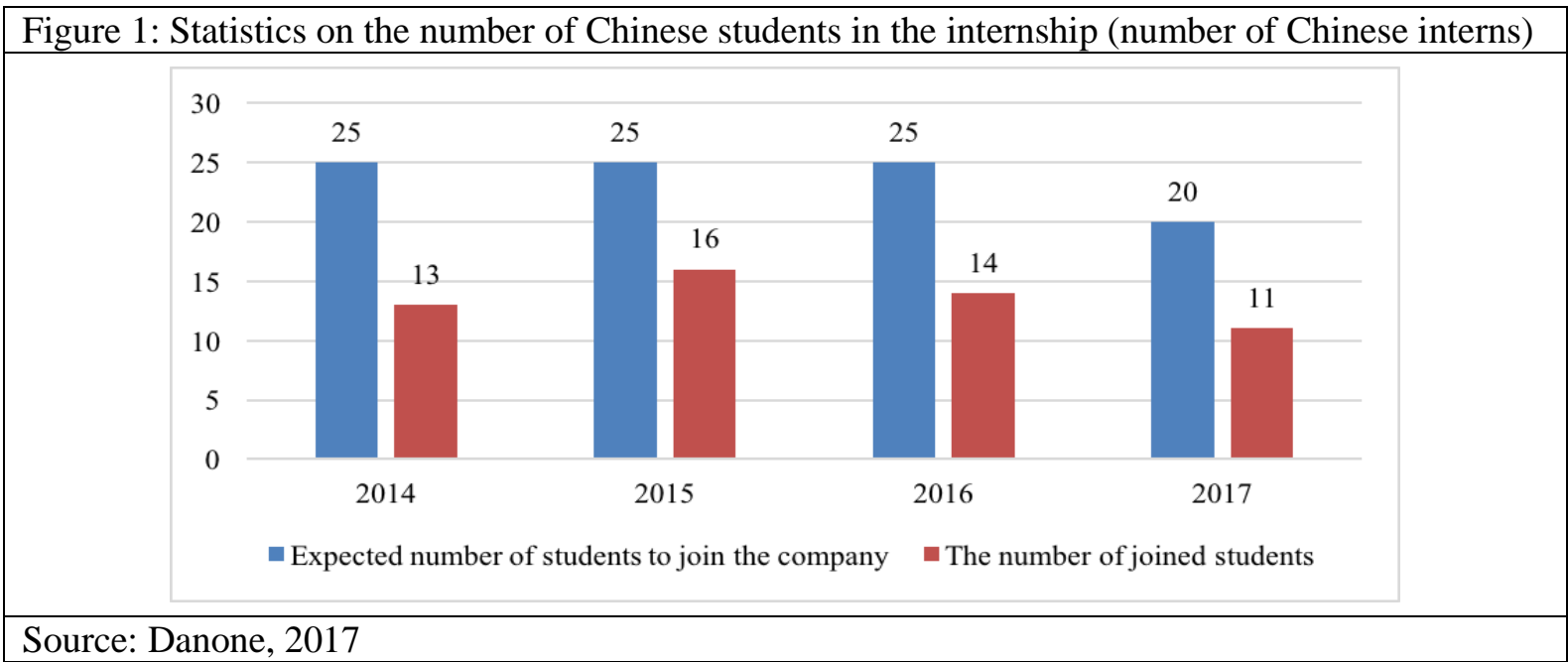

The main goal of this study is to identify whether overall dissatisfaction and issues faced by Chinese interns in France find their roots in cultural differences and to identify which of the areas of internship training are considered most disappointing and cause the interns' reluctance to join Danone China. The hypothesis is that intern dissatisfaction is culture imbedded.

There are two main objectives set for this study. The first objective is to carry out a literature review of key cross-cultural theories and applying them in comparative analysis of the French and Chinese cultures. The second objective is to conduct an empirical study including quantitative research $-\mathrm{a}$ survey among Chinese inters that have participated in the internship programme in Danone (France) with the prospect of being employed by the subsidiary in China and qualitative research - interview with cross-cultural management specialist from China.

\section{Literature review}

Key researchers in the field of cross-cultural communication and management (G.Hofstede, E. Hall, the GLOBE project, F.Trompeenars) provided extensive studies of cultures and their impact on business culture, environment, management and communication.

The uniting factor for the above-mentioned researchers is the proposition of the dimensions based on categorization of cultures, which help to determine the cultural profiles of people (Browaeys and Price, 2015), and enables a more convenient and applicable system of cultural comparisons.

Geert Hofstede being considered a key figure in work-related cultural studies (Dupuis, J., 2014), triggered numerous further studies in the field, based on his ideas. According to his findings, people within an organization behave and react to certain situations in accordance with their "collective programming" meaning the culture (Dabic et al.,2015).

As the result of his cultural research Hofstede has identified six key work-related cultural dimensions: Uncertainity avoidance; Power Distance; Indivisualism/Collectivism; Masculanity/ Femininity; Longterm Orientation; and Indulgence/Restraint. The scores for each dimension differ from country to country. Depending on how high or low the country score is the corresponding management practices, employees' behavior can be observed (Harzing and Pinnington, 2014). According to Gutterman (2010) one of the main aims of the research conducted by Hofstede were to show how the culture of a particular country influenced the leadership practices used in this country. He has criticized the management theorists who stated that the success of managers is based on the talent and their personal preferences in leadership. His survey results were based on the measurements of people's values as employees, not as leaders. By this Hofstede demonstrated that cultural backgrounds and reaction of employees towards certain practices are the factors that shape leadership styles.

According to the GLOBE Foundation (2016) the project GLOBE (the Global Leadership and Organizational Behavior Effectiveness Research Project) founded by its principal investigator Robert J. House in 1991 is today followed by 200 co-researchers in different parts of the world to study the interaction between leadership and culture. In the GLOBE project, R. House and other investigators worked with existing dimensions developed by G. Hofstede. However, the authors not only refined existing dimensions but also added additional ones and, as a result, got variation in the scores. 
Moreover, the researchers of the GLOBE project took a different perspective, they interviewed the managers rather than floor staff, as it was done by Hofstede.

There liability of the research results is proven by its scale: 17,000 managers from 62 different cultures around the world were surveyed. Based on existing theories and the research results, 9 cultural dimensions were suggested: Uncertainity avoidance; Power distance; Future orientation; Gender egalitarianism; Humane orientation; Assertiveness; Performance orientation; In-group collectivism; an Institutional collectivism.

Fons Trompenaars and Charles Hampden-Turner (Schatz and Hoffman, 2016) presented their model of cultural dimensions having surveyed managers in fifty countries to understand the relations of leadership practices and culture. The authors not only identified the critical cultural dimensions of each country they have investigated but, also provided recommendations on how to deal with the cultural differences in Human Resource Management. Kittler et al. (2011) states that unlike the theories developed by Hofstede, the Globe project and Trompenaars, Edaward Hall have developed a communication-oriented model. No other researchers put much attention to the differences in communication methods between cultures than Hall. They have mentioned communication as part of their dimensions however it was not the primary source of them. According to Wood and Wilberger (2015) the work developed by Edward Hall concerning the differences in communication characteristics among cultures, makes him on of the most outstanding researchers in the field of crosscultural management. Edward Hall argued that many problems and misunderstandings were caused by inaccurate intercultural communication. His research was based on the idea that people of different cultural backgrounds had different perceptions of reality and this caused major miscommunications. According to Hall (1990) and Kittler et al. (2011) people tend to unconsciously express non-verbal communication actions which lead him to the suggestion of three dimensions of cross-cultural behavior: Time- represents how people of different cultures view and approach time ( monochromic time and polychromic time); Space- represents the difference in the unconscious level of organizing the personal space among cultures (personal, physical); Context- represents how meanings are constructed differently among cultures using different methods and ways (high-context, low-context)

Characteristics of Chinese and French cultures derived from theories

This part of the study provides a comparative analysis of cultural differnces based on the dimensions proposed by the above mentioned authors. According to the comparison provided by the Hofstede insights (2018) and the findings of the Globe project (Northouse, 2013) both China and France have a high score in Power Distance dimension, meaning that in both countries the hierarchical division within the company is important and respected. In both countries, the power is centralized in the top level of management. However, the fundamental difference comes in the Individualism dimension. Both Hofstede and the GLOBE project in their research have found that France is a highly individualistic country while China has a purely collectivist culture. The representatives of French culture tend to put their own interests in the first place and be appraised for individual achievements rather than group ones. While the Chinese tend to work for the prosperity of the group, the relationships, networking and sharing within a group are important. However, the results of Trompenaars have contradicted the findings of both Hofstede and the GLOBE project. Both countries have been identified having tendencies towards communitarianism meaning that people see themselves as a group rather than individuals (Trompenaars and Hampden-Turner, 2012).

French society, being more feminine than Chinese, gives more attention towards the quality of life and family time. While Chinese society is oriented towards success and competition. People there are prone to sacrifice their family and leisure time for working extra hours.

The second fundamental difference comes in the Uncertainty Avoidance dimension. French people prefer to be prepared in advance, to make detailed plans and schedules, emotional and physical safety are the priorities, that is why the need for rules and regulations is high. The chinese are more comfortable with vagueness and are more flexible in their actions and plans.

Both China and France score high on the Long Term Orientation dimension. This means that both countries are pragmatic. People in both cultures are oriented to achieve results and believe that it is better to save and invest money rather than spending it in a given moment. 
China scores low in the Indulgence dimension, while France is in the middle. This means that people in Chinese society believe that their actions are controlled and somehow limited by the social norms. For them, leisure time and personal desires are not of first importance (The Hofstede Insights, 2018).

According to Trompenaars and Hampden-Turner (2012), France is a universalistic country, meaning that people believe that the laws and regulations are equal for everyone and should be applied regardless of circumstances or the relationships with other people. While China is a highly particularistic country, meaning that people put relationships and circumstances above the rules and the rules could be broken if it will help a person in close relationship with you.

Both countries are in the Affective dimension. However, this does not mean that the countries are the same in exposing their emotions. If in France people openly show their frustration and share their negative or positive opinion about something, Chinese people tend to show their emotions or opinions but they are usually not what they mean. This is explained by the fact that Chinese try to keep "the face" and not to hurt someone's feelings.

France is in the Specific dimension meaning that people do separate private life and work. While China is a Diffuse country, where people emphasize both relationships at work and in everyday life, as building networks and relationships can bring benefits at work as well.

The achievement and ascription dimensions should not be mistaken with Hofstede's Masculine/ Feminine dimensions where the people are either achievement oriented or not. In the Trompenaars dimensions, France is an Achievement country, meaning that people get their status in accordance with their performance. Whereas China is an Ascription country, meaning that the status of the person depends on his age, gender or the social connections he has. (Trompenaars and Hampden-Turner, 2012)

Per the findings of Hall, both China and France are very similar in their perceptions of context, time and space. Like China, France is considered as more high-context culture. Both countries depend on the relationships and networks. The contracts in such countries tend to be short, as a large part of information can be understood within the context. However, there is a degree of the context, which differentiates the countries. If in France there is a tendency to debate, to openly express an opinion, the Chinese tend to hide disagreement with the help of complex phrases and metaphors (Rochefort, 2016) Both China and France are polychronic countries meaning that they put relationships first and then work. Despite of this, a great difference still exists between the countries. French people spend a lot of time on debating even during the meetings at work, while Chinese tend to be short and very up to the point as they believe that debating is a useless expense of time. At the same time, when it comes to schedules, French people tend to follow schedules to higher degree and be prepared for meetings, while Chinese people are more up to improvisation and changes in the schedule (Owen, 2013)

\section{Research process, methodology and design}

The review of the literature discussed in the previous section was used by the authors to develop the theoretical framework for carrying further research. The literature review highlighted that in order to avoid the majority of misunderstandings and conflicts at work the culturally based values and attitudes of employees should be taken into account when constructing the management practices.

Figure 2 presents the theoretical framework of this study that addresses the culturally different behavior of Chinese interns that may have caused dissatisfaction with the internship in France. The framework is composed of two interdependent parts: the dependent variable which is defined as the behavior of Chinese interns and the independent variables which are grouped into two broad categories: culturally driven value variables and culturally driven attitude variables. Both value variables and attitude variables have a straight impact on how people communicate, deal with tasks, schedule their work meatings, the overall behavior at work.

The cross-sectional empirical research was conducted in Bordeaux, France between September and January 2018 among Chinese students that engaged in their internship in Danone.The primary data for this study was collected through the questionnaires distributed using the online survey service Survey Monkey, addressing attitudes, values and challanges of the Chinese interns. Moreover, an additional source of primary data was a face to face interview with the expert in the subject of cross-cultural management and a professor of globalized human ressources management from China. 


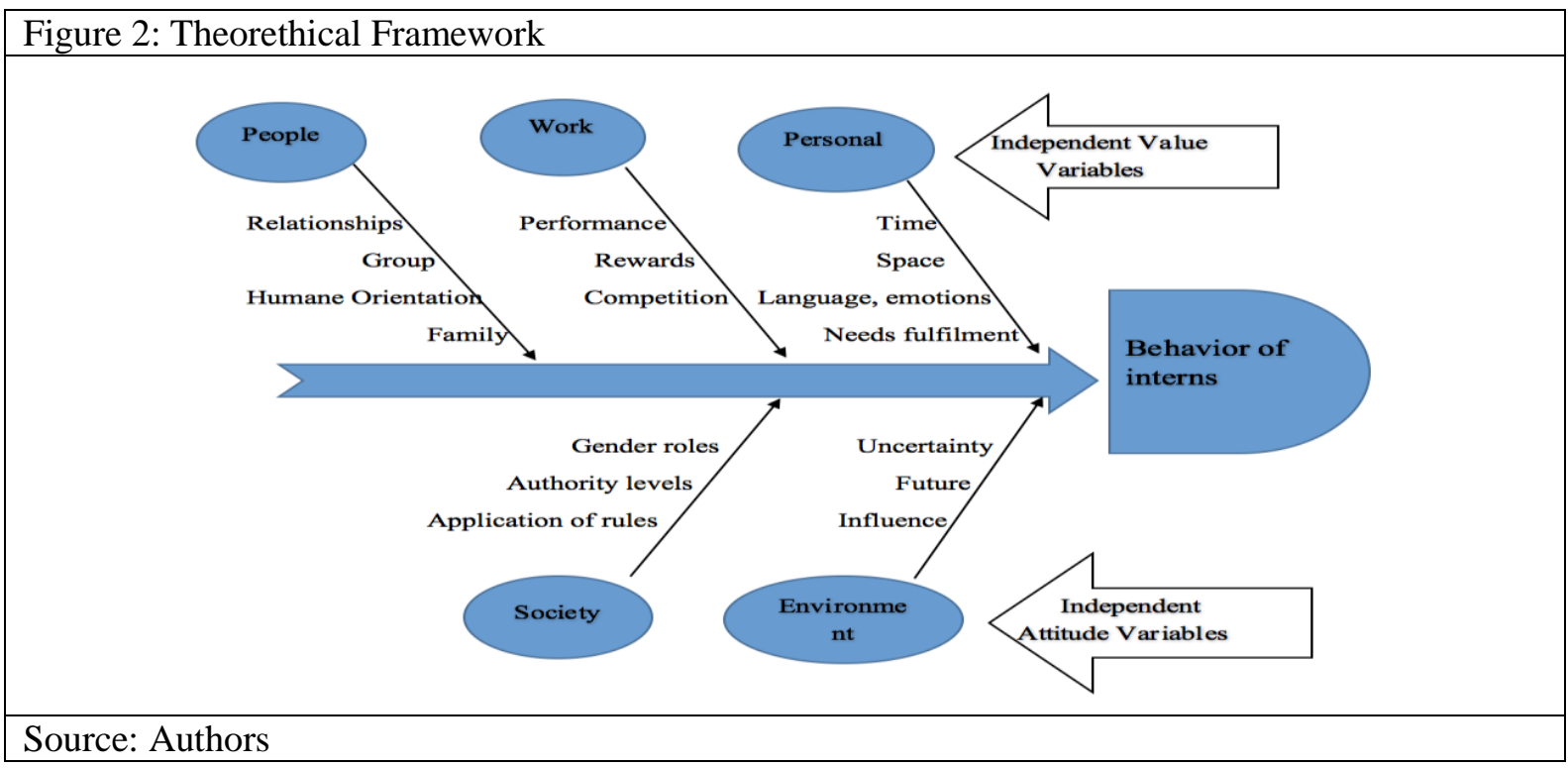

The population of this research is 148 Chinese students that have done a six month internship with Danone during the 4 consequent years. The sampling design of this research is non-probability sampling. The authors used the convenience sampling method. The sample size of this study, identified with the help of an available online service, constituted 107 Chinese interns. The questionnaire comprised two parts. The first part included 16 closed, scale questions that addressed the cultural values of the respondents. The Likert scale was used to measure the degree of agreement or disagreement of the interviewees to certain statement ( from 1 showing the strongest disagreement to 6 showing the strongest agreement). The second part of the questionnaire consisted of 5 open-ended questions related directly to the research problem.

The results and statistics of the questionnaire were analyzed using a frequency distribution method for scale questions and summative content analysis for open-ended questions prior to the interview with the field specialist. The one hour interview with the field specialist in Bordeaux, France consisted of 10 main semi-structured questions based on the analysis of the results obtained from the survey of the Chinese interns. Nevertheless, the authors asked additional questions depending on the answer of the interviewee in order to understand the topic better and to get a more detailed opinion from the specialist.

\section{Findings}

\section{Cultural values of Chinese interns in Danone}

The results have revealed that Chinese interns value the relationships with their colleagues and working in a team the most. $29 \%$ of interns strongly agreed and $47 \%$ agreed that colleagues should support each other when performing a task. Thus, $60 \%$ of the respondents strongly agreed that maintaining relationships with colleagues is important. The field specialist have explained that it was vital for the Chinese interns to build relationships with people they are surrounded with. People take a long time and attention on constructing connections, getting to know each other. This is in the basis of Chinese culture where people build "guanxi"- the network of people they can rely on and trust.

The study has showed not only the importance of a group work for the Chinese interns but the fare distribution of the rewards among the members of a group too. The field expert explains it by the fact that in China people organize themselves into functional teams where the information is shared openly within members in order to perform a task. There is no individual competition, as employees create teams, they compete between the teams as well. In addition, the team reward system is common tradition in Chinese companies; employees feel part of the greater level of success if awarded through the team based approach.

In addition, when it comes to showing disagreement or a negative response, the interns consider it inappropriate or impolite. According to the field specialist, saying "no" or disagreeing directly is considered extremely rude in China. Being a high-context culture, Chinese use very vague expressions to hide the negative direction of their speech. Everything is based on keeping the harmony there, so 
disagreement is considered to break the harmony. The results revealed that the majority $(90 \%)$ feel uncomfortable to express open disagreement. Moreover, 56\% of the interviewed believe that it is impossible to say "no" directly to a person.

The attitude towards schedules and task organization among interns questioned is in majority negative. More than $50 \%$ slightly disagreed with the fact that events should be well planned with minimal possible changes during the process. The field specialist explains this phenomenon from the culture perspective: though Chinese consider time and schedules and value the time of others and usually are punctual, it is more important for them to allow more time for building relationships with colleagues and business partners and to be ready for flexibility and changes in the schedules due to interference or unexpected events. This is related to the perception of environment and relationships in Chinese culture where circumstances may have influence on the process of organization or performance, resulting in the belief that nothing can be fully planned. People usually leave some space for improvisation when planning an event. In addition, when it comes to performance of the task at work, they do not follow the schedules but tend to put in priority the tasks, given by people, with whom they have the best relationships. However, the deadlines for the tasks are considered flexible or changeable, if the person is in good relationships with the demander.

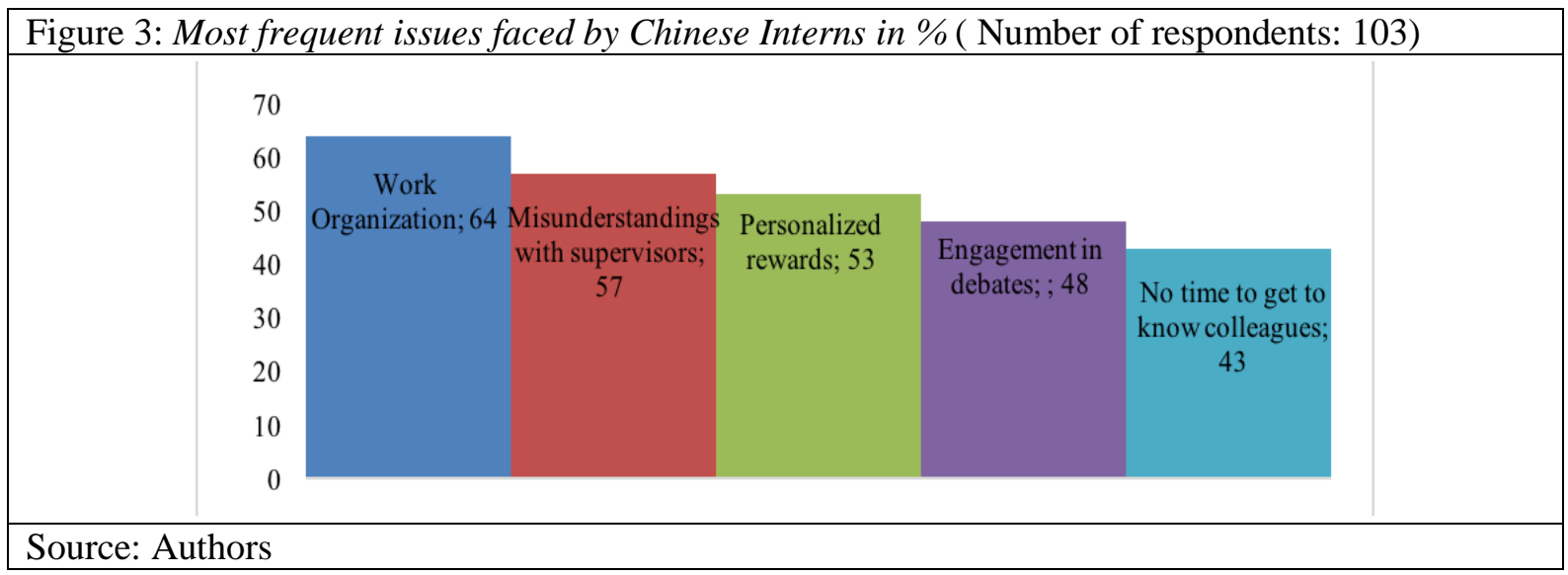

The work related issues faced by the Chinese interns

The most frequent challenge stated by the interns was related to the work organization during the internship (see Figure 3). $64 \%$ of the respondents pointed out feeling isolated from the colleagues because they were not well introduced to people working in the departments, time for networking was not enough or not allocated whatsoever. From the first day, they were assigned a supervisor, with whom they worked during the whole period of the internship. The supervisor would assign the tasks on an individual basis, so the students did not feel a part of the team which caused a substential level of frustration. The second most frequent issue mentioned by the respondents was the problem in communicating with a supervisor. 57\% of the students mentioned misunderstandings with supervisors and claimed that the supervisors were not helpful in explaining the work itself or particular tasks given. Most of the interns stated receiving tasks with no or limited explanations from supervisors. When they addressed themselves to supervisors for more details, they would receive only brief explanations, which did not inhance their efficiency. Students highlighted that they did not want to be impolite and to argue with their curators, so they would quietly take the task and try to do it as they could. Personalized rewards (53\%) were mentioned as the third area of dissatisfaction among the respondents. Many of the students highlighted that they were rewarded individually for the tasks that have been performed in a group, which they considered unfair, as some members of the group were left aboard of the team without any reward. Participation in debates and discussions, $48 \%$ of the respondents stated the need to be engaged in long discussions and debates was considered a challenge they faced. They were encouraged to speak out and share their ideas or recommendations about the issues raised.

\section{Research limitations}

The research was limited in scope, as it has examined the case of one particular company in France and as it concentrates on the differences between French and Chinese cultures and the impact of the 
last on the satisfaction of the interns with the training provided. In addition, the unit of analysis of this research is one of its limitations as only Chinese students that have participated in the internship program of Danone were questioned. Moreover, this research is limited in terms of the response rate of participants, out of 107 necessary respondents only 103 were able to participate. The necessary number of participants was not attained due to the time limitation of this research of 5 months. Furthermore, no discussion or interviews were possible to be arranged among Danone managers, supervising the interns, due to their reluctance to be engaged in the research. This limitation of the research can also serve as a basis for further discussion of internship programme efficiency and supervision at Danone.

\section{Conclusion}

The hypothesis of this study found it's proof in the results of this research as the key problems experienced by the interns found their roots in the difference in cultural values between Chinese and French cultures. Individualism was encouraged in the company however, collectivism is culturally favored among the Chinese. Tasks were individually distributed leaving no possibility for group work and in-group information sharing, no time was allocated for networking among staff and building relationships which is an important factor of communication success for the Chinese.

The procedures of the staff efficiency assessment, practiced in Danone, France, center on evaluating each person individually based on personal inputs even when the work was carried out in a group. This individualistic approach does not comply with the collectivistic cultural principles of Chinese interns, where group work is preferred with sharing information, activities and decisions, and the rewards are distributed among the working groups rather than individuals. The supervisors were not detailed enough when explaining the tasks and were not eager to communicate and support the Chinese-interns, relying more on their initiative and expecting a hands on approach to tasks, whereas the interns were expecting straight directives from the French supervisors and were reluctant to take the initiative.

The interns were feeling under pressure to openly share and discuss their opinions on the decisions taken by the management as it is culturally inappropriate for them. Questioning of the decisions made by the managers and discussing them during meetings was considered disrespectful by the interns. Moreover, the perception of the status of the supervisor did not allow the inters to speak out about the work organization. The students considered long open discussions and debates being useless, as debates and arguments during meetings are not common in China. People tend to try to come to a consensus in decisions to keep the harmony.

The study revealed that key problems experienced by the interns in French management derived from the difference in the following cultural values: collectivism, individualistic rewards, communication, authority perception, achievement and performance orientation. Moreover, the study demonstrated that there is a mismatch between the expectations and preferencies of Chinees interns in communication and networking, time management, job distribution and information sharing, staff assessment and reward and other job-related issues, and the way these are dealt within Danone. Analysis based on cultural dimensions and the field study proves that the mismatch is culture-imbedded and to inhance internship experience to attract new staff to Danone, the programme should be more flexible and adaptable towards the Chinese culture.

However, based on the statement of the limitations of this research and taking into account that the study covered only one particular company in France (extending its activities into Chinese market) the subect of interest should be further investigated. For instance, future research may cover several French companies welcoming Chinese interns. The analysis of their experience could benefit the companies professional staff supply and management activities in China. As companies, extending their activities into the Chinese market undervalue the role of the ethnic culture in management practices, applying their ethnocentric appoach as decades ago, when China was developing mostly as a country for outsourcing business operations. Now when the Chinese economy has reached a leading position in the world ranking, a new approach to managerial staff traning and internship is required as Chinese skilled employees feel more confident in the market and demand more sensitive attention to their cultural values in terms of management and corporate communication. The above mentioned 
creates a strong reason for reconsidering Chinese potential workforce training not only in Danone but any international company operating in China.

\section{References}

Browaeys, M.J, Price, R. (2015) Understanding Cross-Cultural management.3rd ed. Pearson Education Limited

Center on International Education Benchmarking. (2015) Made in China. Retreived January 2015, from:

http://www.ncee.org/china-vet/

Dabic, M., Tipuric, D., Podrug, N. (2015) Cultural differences affecting decision-making style: a comparative study between four countries. Journal of Business Economucs and Management, Volume 6, 2015, Issue 2, pp. 275-289

Danone. (2006) Management- inside stories. Retreived January 2018 , from: http://media.corporateir.net/media_files/irol/95/95168/annualreports/06_indexed/2DANRAP006_7MANAGEMENT_GB.pdf

Danone, (2017). Diversity. Retreived January 2018 , from: http://www.danone.com/en/for-you/candidates/meet-ourpeople/diversity-as-a-source-of-performance/

Dupuis J. (2014) New approaches in cross-cultural management research : The importance of context and meaning in the perception of management styles International Journal of Cross-cultural Management, Vol. 14(1) pp. 67-84

Gutterman, A. (2010) Cross cultural transfer of US theories of leadership and management. Organizational Management and administration: A guide for managers and professionals. Retreived January 2018 , from: http://alangutterman.typepad.com/files/mdc---cross-cultural-transfer-of-us-management-theories.pdf

Hall, E.T.(1990) The Hidden Dimension Anchor Books Editions, pp.23-31

Harzing ,A.W., Pinnington, A. (2014) International Human Resource Management SAGE Publications, Inc., $4^{\text {th }}$ Edition, pp. $9-31$

House, R.J., Hanges, P.J., Javidan,M., Dorfman, P.W.,Gupta, V. (2004) Culture, Leadership and Organizations: the GLOBE study of 62 Societies SAGE Publications, Inc., $3^{\text {rd }}$ Edition, pp. 9-15

Kittler, M.G., Rygl, D., Mackinnon, A. (2011) Beyond Culture or beyond control? Reviewing the use of Hall's high-/lowcontext concept International Journal of Cross-Cultural Management, Volume 11, Issue 1, pp. 63-82

Northouse, P.G.(2013) Leadership: theory and practice SAGE Publications, Inc., $6^{\text {th }}$ Edition, pp.383-405

Owen, A. D. (2013) Time to understand time in China. Retreived January 2018, from:

http://www.2point6billion.com/news/2013/03/20/time-to-understand-time-in-china-12075.htm

Rochefort, P. (2016) Intercultural Management. Retreived January 2018, from:

http://www.understandfrance.org/Business/Intercultural3.html

Schatz, S., Hoffman M. (2016) Advances in Cross Cultural Decision Making. Springer International Publishing, pp. 125-126

The Globe Foundation ( 2016) Culture Visualization. Retreived January 2018, from:

http://globe.bus.sfu.ca/results/countries/CHN?menu=list

The Hofstede Insights (2018) Country comparison Retreived January 2018 , from:

https://www.hofstede-insights.com/product/compare-countries/

Trompenaars, F., Hampden-Turner, Ch. (2012). Riding the Waves of Culture: Understanding Diversity in Global Business. Nicholas Brealey Publishing, $3^{\text {rd }}$ Edition

Wood, V.R., Wilberger, J.S (2015) Globalization, Cultural Diversity and Organizational Commitment: Theoretical Underpinnings World Journal of Management, Volume 6, Number 2, September 2015 Issue, pp. 154-171 